\title{
C/S and B/S mixed structure-based students ideological and political work management system construction
}

\author{
Zhisheng Liu ${ }^{1}$, Kunling Qin², Qiaohui Wang ${ }^{3}$, Qiongqiong $\mathrm{Hu}^{4}$, Yanni Liu ${ }^{1}$ and Bing Zhang ${ }^{1}$ \\ ${ }^{1}$ Institute of Physical Education, Huanggang Normal University, Huangzhou 438000, China \\ 2 Yidu Gaobazhou Middle School, Yidu 443300, China \\ ${ }^{3}$ Macaomiao Primary School, Tuanfeng 438000, China \\ ${ }^{4}$ Fangxian Mengu Middle School, Shiyan 442108, China
}

\begin{abstract}
Nowadays, both single C/S、B/S cannot meet each department demands, for students ideological and political work management construction, it needs $\mathrm{C} / \mathrm{S} 、 \mathrm{~B} / \mathrm{S}$ mixed structure to jointly complete, the paper carries out advantages and disadvantages analysis and judgment on $\mathrm{C} / \mathrm{S}, \mathrm{B} / \mathrm{S}$ single structure, on this basis, utilizes AHP model to analyze $\mathrm{C} / \mathrm{S}$ $、 \mathrm{~B} / \mathrm{S}$ mixed structure in ideological and political work management system, and gets that $\mathrm{C} / \mathrm{S} 、 \mathrm{~B} / \mathrm{S}$ mixed structure obtained recognition degree in students' ideological and political work management is the highest, and analyzes from the ideological and political teachers' operation ability, the students ability to use, ideological and political management system maintenance, and the degree of system coverage four aspects, and gets students ideological and political work management system's system construction strength in $\mathrm{C} / \mathrm{S} 、 \mathrm{~B} / \mathrm{S}$ mixed structure.
\end{abstract}

\section{Introduction}

Software structural design is connecting software demands, due to it gets involved in important bonds, in order to let software designing to arrive at authenticity and feasibility that meets software demands, and then further promotes software quality, in the important link, it can combine $\mathrm{C} / \mathrm{S}$ and $\mathrm{B} / \mathrm{S}$ two kinds of different structures, and fits for students' ideological and political work management system construction, is a kind of common advancement of software development and education mode [1].

$\mathrm{C} / \mathrm{S}$ structure is carrying on that bases on resources asymmetrical conditions, the purpose is to implement resources share and then established system, $\mathrm{C} / \mathrm{S}$ structure divides into client and server two parts, from which server is responsible for data management, client fulfills users interactive work. $\mathrm{C} / \mathrm{S}$ structure has stronger data processing functions, and development is simple, uses non-professional teachers to operate, and $\mathrm{C} / \mathrm{S}$ structure is easier to application program and service construction expansion and compression, in $\mathrm{C} / \mathrm{S}$ structure, clients reaction speed rate is high, but $\mathrm{C} / \mathrm{S}$ structure maintenance cost is very high, and for different operating system, it should establish corresponding version software. In using range, $\mathrm{C} / \mathrm{S}$ structure cannot apply in Internet, it only adapts to local area network, therefore it cannot timely, effective popularize [2-4]. B/S structure belongs to Internet network fields, from which most representative $\mathrm{B} / \mathrm{S}$ structure is browser/ server, it reinforces functions and saves cost. For $\mathrm{B} / \mathrm{S}$ structure, largest advantage is it can operate anywhere, any time, and doesn't need to draw support from any software, comparing to $\mathrm{C} / \mathrm{S}$ structure, $\mathrm{B} / \mathrm{S}$ structure doesn't need to maintain, for ideological and political work administrative staffs, only being able to surf online, and possessing users name and passwords, then can operate. In user version aspect, required systematic configuration is lower, selection is wider. But $\mathrm{B} / \mathrm{S}$ structure server excessive burden affects system efficiency, with visiting amount increases, loading on server will also increase, which also brings inconvenience for upgrading and maintenance [5].

Nowadays both single $\mathrm{C} / \mathrm{Sand} \mathrm{B} / \mathrm{S}$ cannot meet each department demands, in students' ideological and political work management; it also needs high speed, simple system for ideological and political teachers and students' using.

\section{Mold establishments}

\subsection{Construct hierarchical structure}

The paper makes quantization on students' ideological and political work management. Establish target layer, criterion layer and scheme layer relations [6].

Target layer: Students' ideological and political work management system.

Criterion layer: scheme influence factors, $C_{1}$ is ideological and political teachers operation ability, $\mathrm{C}_{2}$ is 
students ability to use, $\mathrm{C}_{3}$ is ideological and maintenance, $\mathrm{C}_{4}$ is the degree of system coverage.

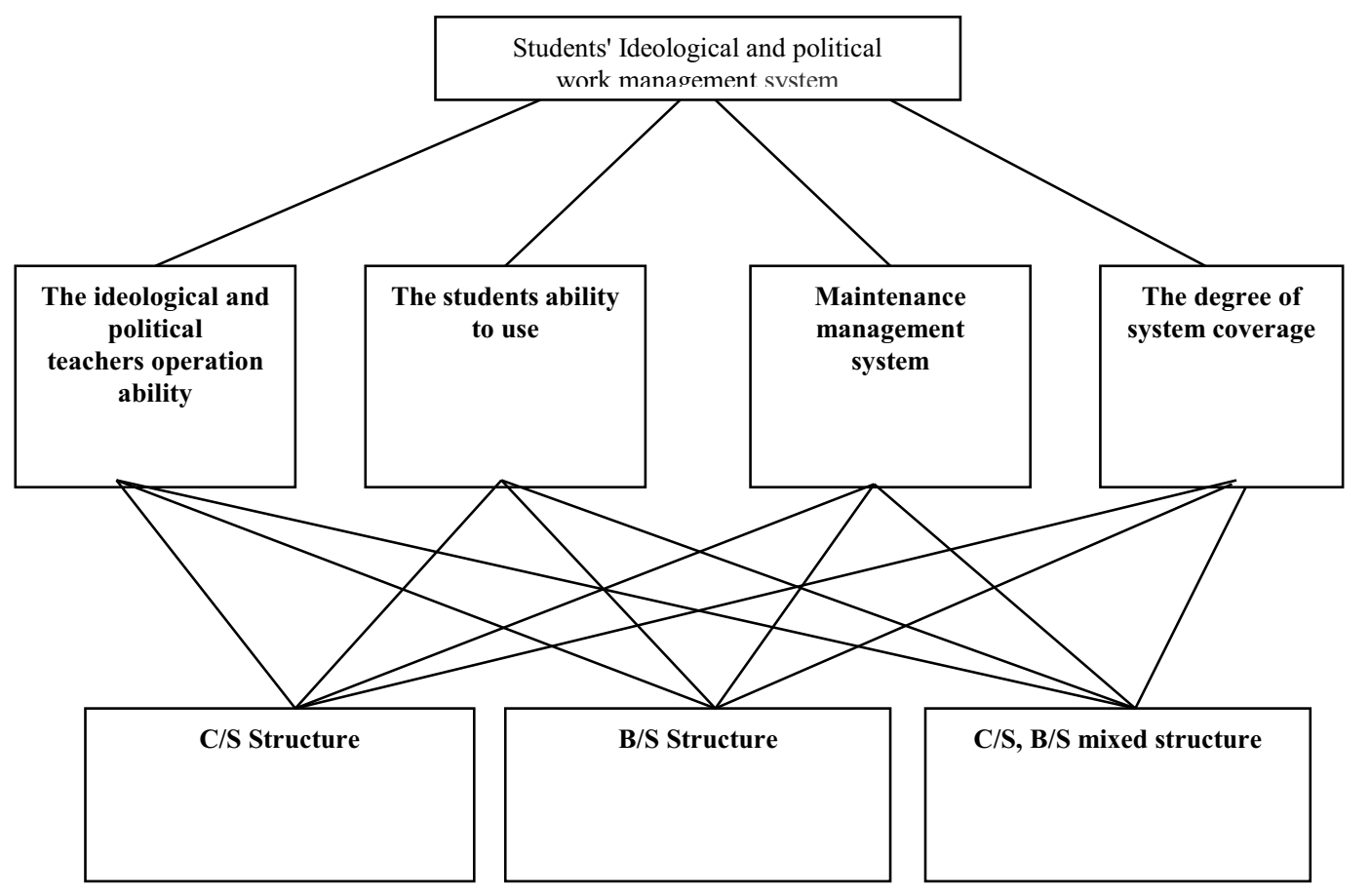

Figure 1. Hierarchical structure.

Scheme layer: $A_{1}$ is $C / S$ structure, $A_{2}$ is $B / S$ structure, $A_{3}$ is $\mathrm{C} / \mathrm{S}, \mathrm{B} / \mathrm{S}$ mixed structure, it gets hierarchical structure as Figure1 shows.

\subsection{Construct each level judgment matrix}

In criterion layer, each criterion target proportion is different, by researchers researching on criterion, and then according to number $1 \sim 9$ and their reciprocals to judge each criterion target proportions.

The paper takes Table 1 showed 1 9 scale table as evidence, carry out weight analysis.

Table 1. 1 9 scale table.

\begin{tabular}{cc}
\hline $\begin{array}{c}\text { Scale } \\
a_{i j}\end{array}$ & Definition \\
\hline 1 & factor $\mathrm{i}$ and factor $\mathrm{j}$ have equal importance \\
3 & factor $\mathrm{i}$ is slightly more important than factor $\mathrm{j}$ \\
5 & factor $\mathrm{i}$ is relative more important than factor $\mathrm{j}$ \\
7 & factor $\mathrm{i}$ is extremely more important than \\
9 & factor $\mathrm{i}$ is absolute more important than factor \\
& $\mathrm{j}$
\end{tabular}

2, 4, 6, Indicates middle state corresponding scale

$8 \quad$ value of above judgments

Recipro If factor $\mathrm{i}$ and factor $\mathrm{j}$ are relative weak, cal obtained judgment is reciprocal
At first, solve judgment matrix, according to above principle, reference 1 9 scale setting, and according to expert's experiences and refer to lots of documents.

\subsection{Hierarchical single arrangement and its consistency test.}

Use consistency indicator to test comparison matrix:

Set in comparison matrix, $\lambda_{\max }$ is maximum feature value, $\mathrm{n}$ is comparison matrix order:

$$
C I=\frac{\lambda_{\max }-n}{n-1}
$$

CI Value gets smaller; it indicates that judgment matrix gets closer to completely consistent. CI Gets bigger, then it shows that known degree is lower.

\subsection{Hierarchical total arrangement and its consistency test.}

$$
A W^{(0)}=\left\{\begin{array}{cccc}
1 & 1 / 3 & 3 & 3 \\
3 & 1 & 5 & 5 \\
1 / 3 & 1 / 5 & 1 & 1 \\
1 / 3 & 1 / 5 & 1 & 1
\end{array}\right\}\left\{\begin{array}{c}
0.2514 \\
0.555 \\
0.0965 \\
0.0965
\end{array}\right\}=\left\{\begin{array}{c}
1.202 \\
2.165 \\
0.287 \\
0.487
\end{array}\right\}
$$

It can get:

$$
\lambda_{\max }^{(0)}=\frac{1}{4}\left(\frac{1.044}{0.267}+\frac{2.244}{0.776}+\frac{0.267}{0.035}+\frac{0.467}{0.088}\right)=4.10 w_{w^{(0)}}=\left(\begin{array}{c}
0.378 \\
0.46 \\
0.064 \\
0.079
\end{array}\right)
$$


Similarly, it can calculate judgment matrix by above steps:

$B_{1}=\left\{\begin{array}{llc}1 & 1 & 1 / 3 \\ 2 & 1 & 1 / 3 \\ 3 & 6 & 1\end{array}\right\}, B_{2}=\left\{\begin{array}{ccc}1 & 5 & 5 \\ 1 / 5 & 1 & 2 \\ 1 / 5 & 1 / 5 & 1\end{array}\right\}, B_{3}=\left\{\begin{array}{ccc}1 & 6 & 8 \\ 1 / 5 & 1 & 5 \\ 1 / 8 & 1 / 5 & 1\end{array}\right\}, B_{4}=\left\{\begin{array}{ccc}1 & 8 & 8 \\ 1 / 5 & 1 & 5 \\ 1 / 8 & 1 / 5 & 1\end{array}\right\}$

By above, it is clear that the paper established and obtained artistic design education mode students' ideological and political work management system maximum feature value and feature vector as weights to analyze, and establishes weight hierarchical figure.

$$
\begin{aligned}
& \lambda_{\text {max }}^{(1)}=3.31, \omega_{1}^{(1)}=\left\{\begin{array}{l}
0.262 \\
0.078 \\
0.67
\end{array}\right\} \\
& \lambda_{\text {max }}^{(2)}=3.12, \omega_{2}^{(1)}=\left\{\begin{array}{l}
0.565 \\
0.297 \\
0.138
\end{array}\right\} \\
& \lambda^{(3)}{ }_{\text {max }}=3.30, \omega^{(1)}{ }_{3}=\left\{\begin{array}{l}
0.633 \\
0.230 \\
0.137
\end{array}\right\} \\
& \lambda^{(4)}{ }_{\text {max }}=4.05, \omega^{(1)}{ }_{4}=\left\{\begin{array}{l}
0.173 \\
0.251 \\
0.576
\end{array}\right\}
\end{aligned}
$$

Use consistency indicator to test feature value:

$$
C I=\frac{\lambda_{\max }-n}{n-1}, C R=\frac{C I}{R I}
$$

By Table 2, and then by obtained judgment matrix $A$, $\lambda_{\text {max }}^{(0)}=4.073, R I=0.9$ calculate and get:

$$
C I=\frac{4.073-4}{4-1}=0.239 \quad C R=\frac{C I}{R I}=\frac{0.239}{0.90}=0.027<0.1
$$

Due to $\mathrm{CR}<0.1$, it can get that A inconsistency extent is efficient and moves within permissible range of table, it can use A feature vector to replace weight vector.

(2) Similarly, to judgment matrix $\mathrm{B}_{1}, \mathrm{~B}_{2}, \mathrm{~B}_{3}, \mathrm{~B}_{4}$ it carries out consistency test, and get weight vector. The paper utilizes hierarchical chart drawing out calculation results from object layer to scheme layer, as Figure 3 shows.

Calculation result is as following:

$$
\begin{aligned}
w & =w^{(1)} w^{(0)} \\
& =\left\{\begin{array}{cccc}
0.261 & 0.584 & 0.634 & 0.175 \\
0.078 & 0.278 & 0.231 & 0.251 \\
0.68 & 0.138 & 0.135 & 0.574
\end{array}\right\}\left\{\begin{array}{l}
0.557 \\
0.066 \\
0.124 \\
0.253
\end{array}\right\} \\
& =\left\{\begin{array}{l}
0.195 \\
0.222 \\
0.583
\end{array}\right\}
\end{aligned}
$$

Table 2. RI value.

\begin{tabular}{cccccccccccc}
\hline $\mathrm{n}$ & 1 & 2 & 3 & 4 & 5 & 6 & 7 & 8 & 9 & 10 & 11 \\
\hline $\mathrm{RI}$ & 0 & 0 & 0.58 & 0.90 & 1.12 & 1.24 & 1.32 & 1.41 & 1.45 & 1.49 & 1.51 \\
\hline
\end{tabular}

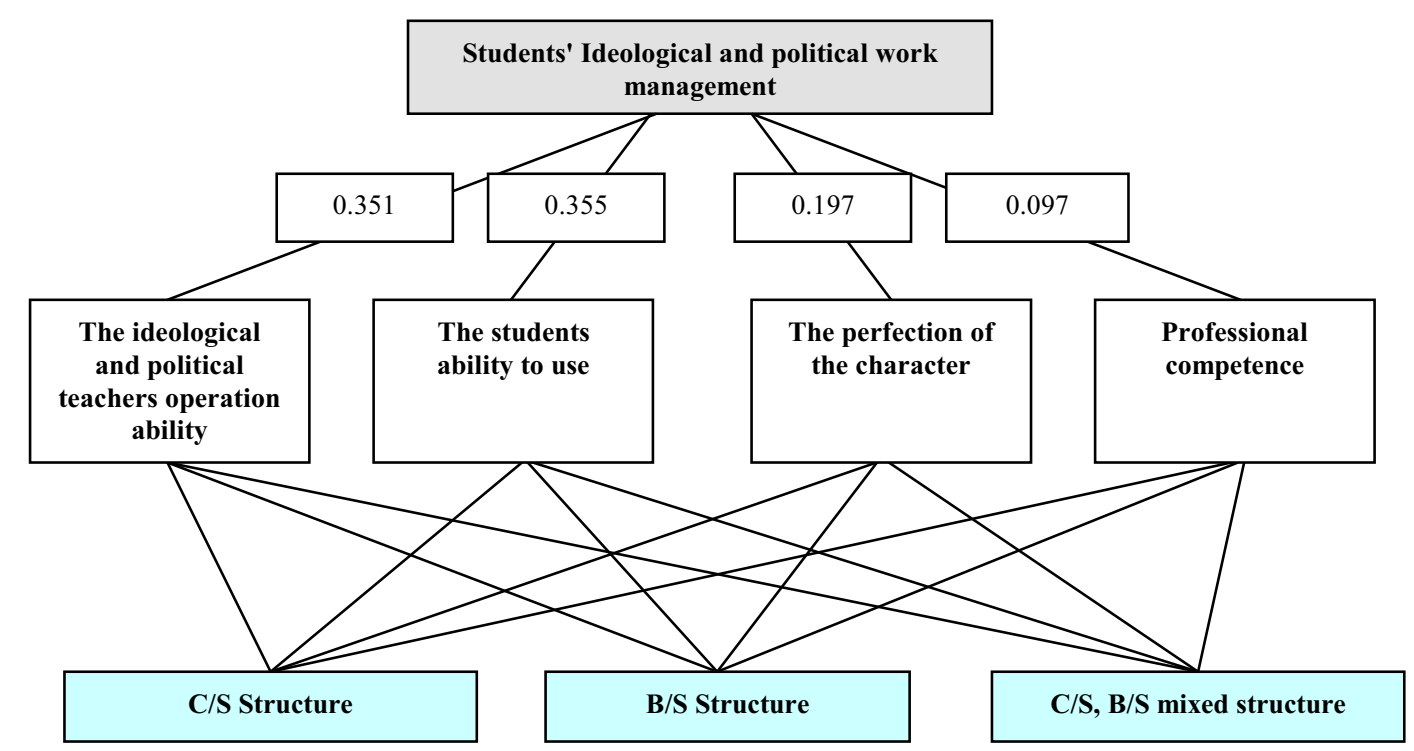

Figure 3. Hierarchical structure chart. 


$$
\begin{aligned}
\omega^{(1)} & =\left(\omega_{1}^{(1)}, \omega_{2}^{(1)}, \omega_{3}^{(1)}, \omega_{3}^{(1)}\right) \\
& =\left\{\begin{array}{cccc}
0.615 & 0.174 & 0.263 & 0.584 \\
0.223 & 0.251 & 0.078 & 0.2776 \\
0.156 & 0.575 & 0.66 & 0.139
\end{array}\right\}
\end{aligned}
$$

By calculation, the paper gets: students' ideological and political work management system, $\mathrm{C} / \mathrm{S}$ structure proportion is $19.5 \%, \mathrm{~B} / \mathrm{S}$ structure is $22.2 \%$ of total proportions. $\mathrm{C} / \mathrm{S} 、 \mathrm{~B} / \mathrm{S}$ mixed structure occupies $58.3 \%$ of total proportions.

\section{Conclusions}

The paper analyzes from the ideological and political teachers' operation ability, the students ability to use, ideological and political management system maintenance, and the degree of system coverage four aspects, and gets students ideological and political work management system's system construction strength in $\mathrm{C} / \mathrm{S}, \mathrm{B} / \mathrm{S}$ mixed structure, and analyzes from $\mathrm{C} / \mathrm{S}$ structure and $\mathrm{B} / \mathrm{S}$ structure individual structure, on the basis of modern network universality, gets $\mathrm{B} / \mathrm{S}$ structure adaptability is higher, but due to $\mathrm{B} / \mathrm{S}$ structure drawbacks, it let $\mathrm{C} / \mathrm{S} 、 \mathrm{~B} / \mathrm{S}$ mixed structure adaptability to increase. It simplifies teachers and students' operation, reduces maintenance cost and increases coverage area.

\section{References}

1. Z.L. Liu, IJACT, 5, 5 (2013).

2. C.L. Zhou, China oil and chemical engineering, 10 (2009).

3. H.M. Liu, Computer and modernization, 11 (2007).

4. Y.W. Wang, H.L. Deng, Y.C. Wang, Heilongjiang water science and technology 03 (2007).

5. X.J. Yang, X.M. Song, Electronic products manufacturing equipment 01 (2011).

6. D.J. Hu, L. Xue, Journal of Mechanical Engineering Research and Developments 38, 1 (2015). 